\title{
INVESTIGATION OF HIGH-EFFICIENCY SCREEN-PRINTED TEXTURED SI SOLAR CELLS WITH HIGH SHEET- RESISTANCE EMITTERS
}

\author{
Mohamed M. Hilali, Kenta Nakayashiki, Abasifreke Ebong and Ajeet Rohatgi \\ University Center of Excellence for Photovoltaics Research and Education, \\ School of Electrical and Computer Engineering, Georgia Institute of Technology, Atlanta, GA 30332-0250
}

\begin{abstract}
In this study it is found that the efficiency enhancement $(\Delta \eta)$ resulting from the use of a $100 \Omega / s q$ emitter instead of a conventional $45 \Omega /$ sq emitter is substantially enhanced further by surface texturing. This enhancement is greater for textured cells by at least $\sim 0.4 \%$ absolute over the enhancement for planar cells, and is mainly due to the greater difference in the frontsurface recombination velocity (FSRV) between the highand low-sheet-resistance emitter textured cells. A FSRV of $60,000 \mathrm{~cm} / \mathrm{s}$ resulted in a reasonably good $V_{\text {oc }}$ of $\sim 642$ $\mathrm{mV}$ for the $100 \Omega / \mathrm{sq}$ emitter textured cell. Our investigation of the $\mathrm{Ag}$-Si contact interface shows a more regular distribution of $\mathrm{Ag}$ crystallite precipitation for the textured emitter (mainly at the peaks of the texture pyramids). The high contact-quality resulted in a series resistance of $0.79 \Omega-\mathrm{cm}$, a junction leakage current of $18.5 \mathrm{nA} / \mathrm{cm}^{2}$ yielding a FF of 0.784 . This resulted in a record high-efficiency $4 \mathrm{~cm}^{2}$ screen-printed cell of $18.8 \%$ (confirmed by NREL) on textured $0.6 \Omega$-cm FZ, with single-layer antireflection coating.
\end{abstract}

\section{INTRODUCTION}

The cost performance targets of Si photovoltaics can be reached by enhancing cell efficiency while utilizing high throughput processing [1]. Front-surface texturing and high sheet-resistance emitters have consistently enhanced the solar cell performance resulting in high efficiencies [2-4]. However, they have not yet been implemented together using the simple conventional screen-printed cell processing (i.e. single-step diffusion and co-firing of the screen-printed contacts). Therefore, in this study, we have investigated the combination of high sheet-resistance emitters with surface texturing using screen-printed contacts. We have previously demonstrated high fill factors $(>0.78)$ on high sheetresistance planar emitters through understanding and optimization of an appropriate $\mathrm{Ag}$ paste and firing recipe [5]. This led to the fabrication of $17.4 \%$-efficient solar cells on float-zone Si with screen-printed contacts on a planar $100 \Omega /$ sq phosphorus-doped emitter. In this paper we report on the investigation of textured high sheetresistance emitters. Both the short-wavelength response and the screen-printed contact behavior for high sheetresistance emitter textured cells have been investigated. A study of these factors has been also performed for planar cells.

\section{EXPERIMENTAL}

In this study, screen-printed (SP) $n^{+}-p-p^{+}$solar cells $\left(4 \mathrm{~cm}^{2}\right)$ are fabricated on single-crystal p-type, $300-\mu \mathrm{m}$ thick (100) float-zone (FZ) substrates. First, textured and planar FZ silicon wafers received a standard RCA clean followed by $\mathrm{POCl}_{3}$ diffusion to form the $\mathrm{n}^{+}$-emitter. A diffusion temperature of $843^{\circ} \mathrm{C}$ was used for the 100 $\Omega / \mathrm{sq}$ emitter while $878^{\circ} \mathrm{C}$ was used for the $45 \Omega / \mathrm{sq}$. After the phosphorus-glass removal and another clean, $50 \mathrm{kHz}$ PECVD SiN $\mathrm{N}_{\mathrm{x}}$ AR coating was deposited on the emitter. Next, an Al paste was screen-printed on the backside and dried at $200^{\circ} \mathrm{C}$. The $\mathrm{Ag}$ grid was then screen-printed on top of the $\mathrm{SiN}_{\mathrm{x}}$ film and then the $\mathrm{Ag}$ and Al contacts were co-fired (single firing step) in a lamp-heated threezone infra-red belt furnace. Cells were then isolated using a dicing saw and then subjected to a 15-min. forming-gas anneal. The cell performance was characterized by light I-V as well as internal quantumefficiency (IQE) measurements for the short-wavelength response. Textured cells were used with planar back to ensure that the base properties were the same when comparing planar and textured cells. Cells with surface texturing on both sides were also fabricated.

\section{RESULTS AND DISCUSSION}

As shown in Fig. 1 the short-wavelength response for a textured emitter is lower than that for the planar emitter. This is attributed to the higher front-surface recombination velocity because of the increase in surface area due to the textured surface. Nevertheless, the lower reflectance due to texturing results in a 3.94 $\mathrm{mA} / \mathrm{cm}^{2}$ enhancement in transmitted current over the planar surface, calculated from the reflectance curves in Fig. 2. Therefore, the loss in short-wavelength response shown in Fig. 1 is relatively negligible.

As shown in Fig. 3, the enhancement in efficiency due to the $100 \Omega / s q$ emitter compared with a $45 \Omega / s q$ emitter is significantly more pronounced for textured cells

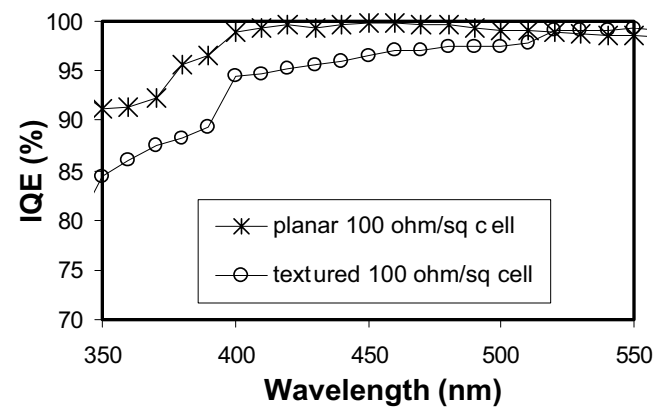

Fig. 1: Short-wavelength response of planar versus textured $100 \Omega /$ sq emitters. 


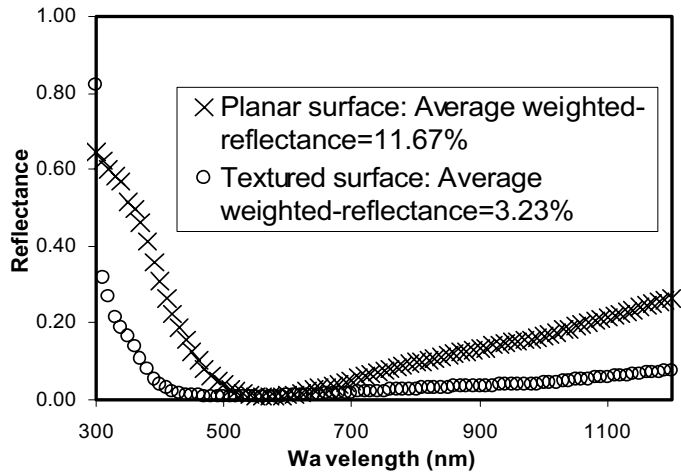

Fig. 2: Reflectance of planar and textured emitter surface with $\mathrm{SiN}_{\mathrm{x}}$ single-layer antireflection coating.

compared with planar cells. The higher $\Delta \eta$ shown in Fig. 3 for textured cells is a result of a higher $\Delta \mathrm{Jsc}$ by $\sim 0.4$ $\mathrm{mA} / \mathrm{cm}^{2}$ for the textured cells compared with the planar cells (Table 1). The improvement in $\mathrm{J}_{\mathrm{sc}}\left(\Delta \mathrm{J}_{\mathrm{sc}}\right)$ due to the $100 \Omega /$ sq over a $45 \Omega /$ sq emitter for textured cells is $\sim 1.2$ $\mathrm{mA} / \mathrm{cm}^{2}$ while that for planar cells is $\sim 0.8 \mathrm{~mA} / \mathrm{cm}^{2}$ for the $0.6 \Omega-\mathrm{cm}$ base resistivity. The $V_{\text {oc }}$ enhancement for textured cells is the same as for the planar cells, and the fill factors are within close range for the textured and planar cells with the same emitter sheet-resistance. Therefore, we investigated the IQE as well as the spectral response (SR) for the 45 and $100 \Omega$ /sq textured and planar cells to better understand the difference in $\Delta \mathrm{J}_{\mathrm{sc}}$ between planar and textured cells. $\mathrm{SR}$ is expressed as: $\operatorname{SR}(\lambda)=\operatorname{IQE}(\lambda)(1-\operatorname{R}(\lambda)) \cdot(\lambda / 1.24)$,

where IQE is the internal quantum efficiency, $R$ is the reflectance of the cell, and $\lambda$ is the wavelength in $\mu \mathrm{m}$.

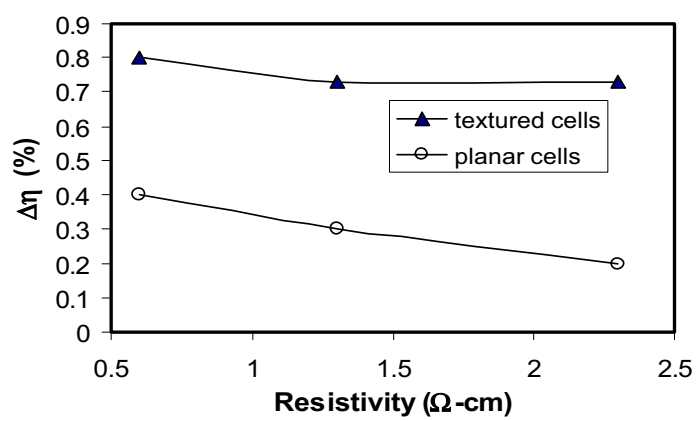

Fig. 3: Measured enhancement in efficiency due to a $100 \Omega /$ sq versus a $45 \Omega / s q$ emitter for textured and planar cells with different base resistivity.

Table 1: Light I-V parameters of $0.6 \Omega$-cm textured and planar best cells with 45 and $100 \Omega /$ sq emitters.

\begin{tabular}{|c|c|c|c|c|c|c|c|}
\hline $\begin{array}{l}\text { Emitter } \\
\text { Surface }\end{array}$ & $\begin{array}{c}\text { Emitter } \\
(\mathbf{Q} / \mathrm{sq})\end{array}$ & $\begin{array}{l}V_{o c} \\
(m V)\end{array}$ & $\begin{array}{c}\mathrm{J}_{\mathrm{sc}} \\
\left(\mathrm{mA} / \mathrm{cm}^{2}\right)\end{array}$ & $\begin{array}{c}\text { AJsc } \\
\left(\mathrm{mA}^{2} \mathrm{~cm}^{2}\right)\end{array}$ & FF & Eff $(\%)$ & $\Delta \eta(\%)$ \\
\hline \multirow{2}{*}{ Planar } & 45 & 636 & 33.8 & \multirow{2}{*}{0.8} & 0.786 & 17.0 & \multirow{2}{*}{0.4} \\
\hline & 100 & 646 & 34.6 & & 0.780 & 17.4 & \\
\hline \multirow{2}{*}{ Textured } & 45 & 632 & 35.7 & \multirow{2}{*}{1.2} & 0.781 & 17.6 & \multirow{2}{*}{0.8} \\
\hline & 100 & 642 & 36.9 & & 0.778 & 18.4 & \\
\hline
\end{tabular}

A. Investigation of the Short-Wavelength Response

There are three possibilities for the greater enhancement in $\mathrm{J}_{\mathrm{sc}}$ for the textured high sheet-resistance emitter compared with the low sheet-resistance emitter. The first factor investigated is the enhancement in IQE $(\triangle \mathrm{IQE}$, the enhancement in IQE due to the high sheetresistance emitter) due to the longer light path for a textured emitter versus a planar emitter. The increased light path increases absorption for a textured surface since the absorption for a textured surface is $\alpha_{\text {tex }}=\alpha_{p l} / \cos (\theta)$ where $\alpha_{p l}$ is the absorption for a planar surface and $\theta$ is the refracted angle [6]. The effect of the increased optical path-length in textured cells was simulated in PC1D for $45 \Omega / s q$ and $100 \Omega / s q$ cells. Figure 4 shows that the short-wavelength IQE was almost identical for the $100 \Omega / \mathrm{sq}$ textured and planar cells when other device parameters (i.e. FSRV) were unchanged. Similarly, the short-wavelength IQE results were almost identical for the simulated cells with $45 \Omega / s q$ planar and textured emitter with the same FSRV. Therefore, the difference in the light path-length in a textured emitter versus a planar emitter has a negligible effect on the improvement due to the high sheetresistance emitter.

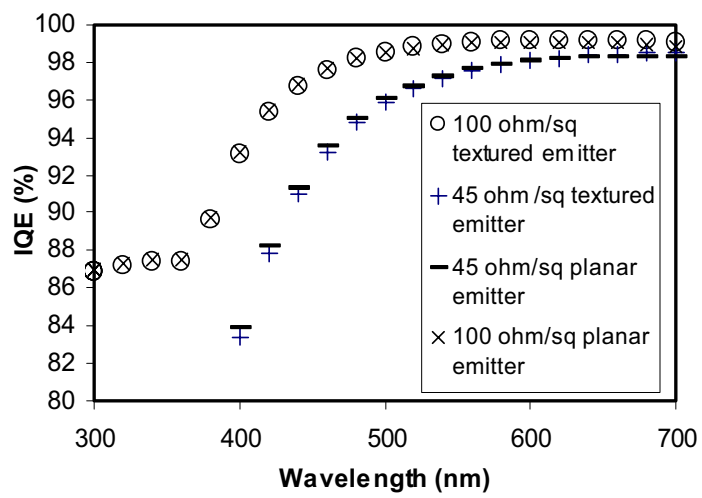

Fig. 4: PC1D-simulated short-wavelength response for textured and planar 100 and $45 \Omega /$ sq emitter cells. FSRV is the same for all cases.

The second effect resulting in the higher $\Delta \mathrm{J}_{\mathrm{sc}}$ and higher $\Delta \eta$ is due to the lower reflectance of the textured surface, which would result in a greater enhancement due to the high-sheet resistance emitter as compared to the enhancement for a planar emitter with the same passivation. This can be described by the following simple equation: $\Delta \operatorname{SR}(\lambda)=\Delta \operatorname{IQE}(\lambda)(1-\mathrm{R}(\lambda)) \cdot(\lambda / 1.24)$, where $\Delta S R$ is the enhancement in spectral response due to $\triangle \mathrm{IQE}$. Therefore, for a lower reflectance the enhancement in spectral response due the high sheetresistance emitter would be more pronounced. For the reflectance values obtained from Fig. $2, \Delta \mathrm{J}_{\mathrm{sc}}$ for the textured emitter would be more pronounced by a factor of 1.096 compared to the planar emitter. However, this factor does not account for more than $\sim 0.1 \mathrm{~mA} / \mathrm{cm}^{2}$ of the improvement in $\Delta \mathrm{J}_{\mathrm{sc}}$ in favor of the textured cells. This is also in agreement with PC1D modeling results assuming that the FSRV is the same for textured and planar cells for the same emitter (i.e. $\Delta \mathrm{IQE}_{\mathrm{tex}} \sim \Delta \mathrm{IQE}_{\mathrm{pl}}$ ).

The third aspect investigated is the FSRV difference between textured and planar cells for 100 and $45 \Omega / s q$ emitters. This was found to be the main effect that results 
in the greater performance enhancement observed due to the high sheet-resistance emitter for textured cells. This is because the change in FSRV between the 100 and $45 \Omega /$ sq emitter is greater for textured than for planar cells. In order to prove this behavior the FSRV was extracted by matching the measured short-wavelength IQE with the PC1D-modeled IQE for planar and textured cells. As an example of the FSRV extraction, the measured and simulated short-wavelength IQE for a FZ cell with a $100 \Omega /$ sq textured emitter is shown in Fig. 5 . The extracted FSRV values for each case are shown in Table 2. The textured surface results in an area 1.73 times greater than that of the planar surface. The extracted FSRV values are in agreement with this area factor as shown in Table 2, where the FSRV for the textured emitter is $\sim 1.7$ times greater than that of the planar emitter, for the same emitter sheet-resistance. This is observed for both 45 and $100 \Omega$ /sq emitters. As shown in Table 2, the effect of the FSRV change is more pronounced for the textured versus planar emitters resulting in a greater change in FSRV when going from the $45 \Omega / \mathrm{sq}$ emitter to the $100 \Omega / \mathrm{sq}$ emitter. This is because the effect of FSRV increase due to the textured area factor has less of an impact for the $100 \Omega$ /sq emitter

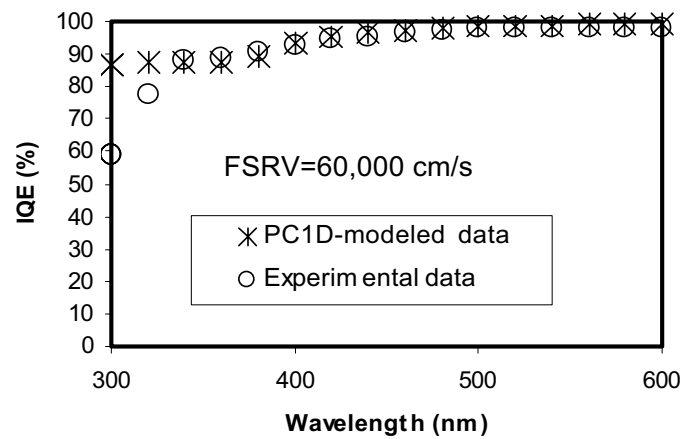

Fig. 5: IQE matching of experimental shortwavelength response data using PC1D-modeled data for $100 \Omega /$ sq emitter textured cell.

with lower FSRV $(35,000 \mathrm{~cm} / \mathrm{s}$ for the planar emitter increases to $60,000 \mathrm{~cm} / \mathrm{s}$ for the textured emitter) compared with the $45 \Omega / \mathrm{sq}$ emitter with a significantly higher FSRV $(90,000 \mathrm{~cm} / \mathrm{s}$ for the planar emitter increases to $150,000 \mathrm{~cm} / \mathrm{s}$ for the textured emitter). Consequently, this more pronounced effect is reflected in the greater efficiency enhancement $(\Delta \eta)$ for textured cells as shown in Fig. 3 . The effect of the FSRV change for textured versus planar emitters is the main factor that results in the greater enhancement in $\Delta \mathrm{Jsc}$ of $\sim 0.3$ $\mathrm{mA} / \mathrm{cm}^{2}$ and $\Delta \eta$ of $\sim 0.3 \%$ absolute in favor of textured cells. Using the FSRV values in Table 2, PC1D simulation results show an enhancement of $\sim 0.4 \mathrm{~mA} / \mathrm{cm}^{2}$ in $\Delta \mathrm{Jsc}$ and $0.4 \%$ absolute in $\Delta \eta$ in favor of textured cells

Table 2: Extracted FSRV values for 45 and 100 $\Omega /$ sq textured and planar emitters.

\begin{tabular}{|c|c|c|c|}
\hline Emitter $\rho_{s}(\Omega / s q)$ & TexturediPlanar & FSRV $(\mathrm{cm} / \mathrm{s})$ & FSRV Factor Due to Textured Surface \\
\hline 45 & planar & 90,000 & \multirow{2}{*}{1.67} \\
\hline 45 & textured & 150,000 & \\
\hline 100 & planar & 35,000 & \multirow{2}{*}{1.71} \\
\hline 100 & textured & 60,000 & \\
\hline
\end{tabular}

for a $0.6 \Omega$-cm base resistivity, which supports the experimental results in Fig. 3.

\section{B. Contact Interface Study}

We have also investigated the contact interface for both textured and planar high sheet-resistance emitter cells. Figure 6 shows top-view SEM images of the area underneath the Ag gridline $(25 \times 25 \mu \mathrm{m})$ after etching away the bulk metal of the gridline and the glass layer. As shown in Fig. 6(a) the planar surface has a more irregular distribution of $\mathrm{Ag}$ segregation (or Ag crystallite precipitation) compared with the textured emitter surface in Fig. 6(b). Figure 6(b) shows that there is $\mathrm{Ag}$ precipitation at the peaks of the texture pyramids even in regions where the $\mathrm{Ag}$ crystallite precipitation is sparse. However, this is not the case for the planar surface where many regions are void of $\mathrm{Ag}$ crystallite precipitation. This results in a less regular distribution of Ag crystallites for the planar emitter surface as opposed to the textured emitter surface. This may explain the smaller standard deviation of $0.48 \Omega-\mathrm{cm}^{2}$ in the series resistance for textured emitter cells compared with a standard deviation of $1.19 \Omega-\mathrm{cm}^{2}$ for planar emitter cells. This may be attributed to the ease with which the glass frit can etch through the $\mathrm{SiN}_{\mathrm{x}}$ layer for a textured surface, particularly at the peaks of the pyramids, compared with a planar emitter surface. However, more work is needed to support this result and to prove that it is not a surface orientation effect (i.e. (111) for a textured surface versus (100) for a planar surface). The fill factors achieved on the high-performance textured and planar $100 \Omega /$ sq cells are very close comparing the high efficiency cells.

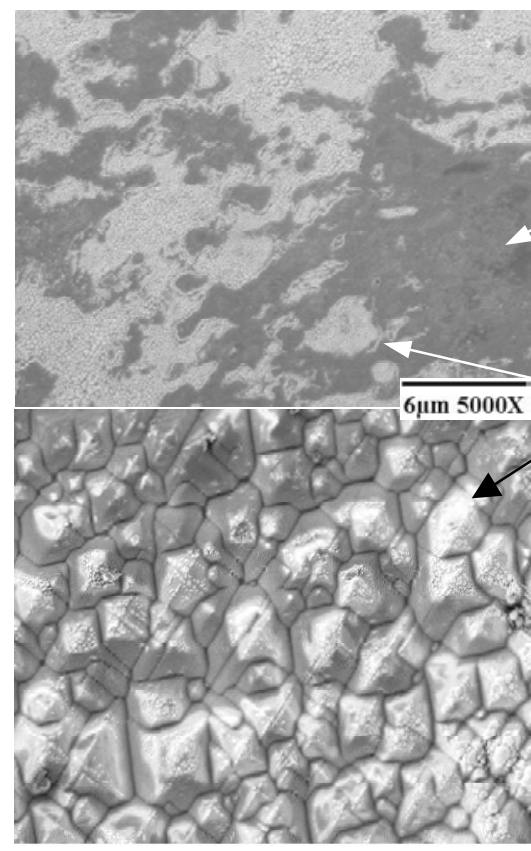

(a)

No $\mathrm{Ag}$ crystallite preipitation $\mathrm{Ag}$ crystallite preipitation

Fig 6: SEM top-view images of the region underneath the screen-printed contact for (a) planar emitter, and (b) textured emitter.

C. Record High-Efficiency Cell and Device Modeling Through the understanding and implementation of 
the above effects, we have fabricated record highefficiency screen-printed cells of $18.8 \%$ with a textured $100 \Omega / s q$ emitter (independently confirmed by NREL using a mask aperture area of $3.802 \mathrm{~cm}^{2}$ ). This cell has $0.6 \Omega$-cm base resistivity and a single-layer antireflection coating (PECVD $\mathrm{SiN}_{\mathrm{x}}$ ), the original cell area is $4 \mathrm{~cm}^{2}$. This high-efficiency is primarily due to the high current of $37.3 \mathrm{~mA} / \mathrm{cm}^{2}$ and high FF of 0.784 (Fig. 7) while maintaining a good $\mathrm{V}_{\text {oc. }}$. This high $\mathrm{FF}$ is made possible by the low series resistance of $0.79 \Omega-\mathrm{cm}^{2}$ as well as the low $\mathrm{J}_{02}$ value of $\sim 18 \mathrm{nA} / \mathrm{cm}^{2}$, which shows that the $p-n-$ junction was not badly affected by the paste firing even at the peaks of the pyramid texture. The $V_{o c}$ is also maintained to a reasonably good value of $641.5 \mathrm{mV}$ for the textured SP $100 \Omega / \mathrm{sq}$ emitter cell. This $\mathrm{V}_{\text {oc }}$ is close to the $\mathrm{V}_{\text {oc }}$ of the planar $100 \Omega / \mathrm{sq}$ cell of $\sim 646 \mathrm{mV}$, which indicates the small loss in $\mathrm{V}_{\text {oc }}$ due to the change in FSRV from $35,000 \mathrm{~cm} / \mathrm{s}$ to $60,000 \mathrm{~cm} / \mathrm{s}$ due to texturing (Table $2)$. Ten cells were confirmed by NREL with efficiencies in the range of $18.4 \%$ to $18.9 \%$ on $0.6 \Omega-\mathrm{cm}$ as well as $1.3 \Omega-\mathrm{cm}$ with both sides textured.

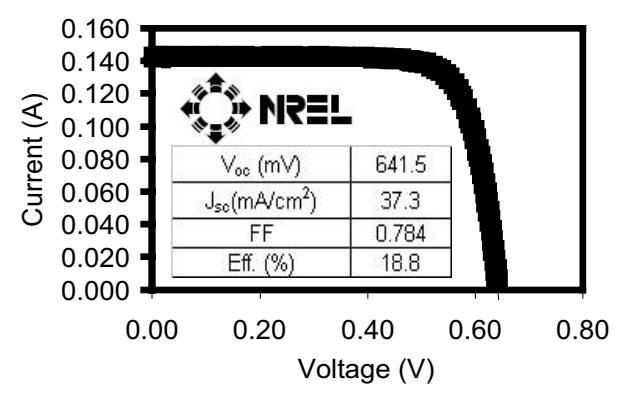

Fig. 7: I-V measurement by NREL for the $18.8 \%$ textured front and back $100-\Omega /$ sq emitter cell.

Table 3 shows the PC1D device modeling parameters for an $18.6 \% 100 \Omega / s q$ textured cell (also confirmed by NREL). The modeled parameters are obtained by matching the short- and long-wavelength IQE response while using the measured reflectance of the cell. The variation in the second-diode ideality factor $\left(n_{2}\right)$ is probably responsible for the observed cell efficiency variation of $0.4 \%$ absolute for several highefficiency cells fabricated in the same way. In agreement with the findings of Weeber et al. [7], our device modeling indicates that a better front-surface passivation $(<20,000 \mathrm{~cm} / \mathrm{s})$ is necessary for further improvement of the $100 \Omega / \mathrm{sq}$ textured $\mathrm{FZ}$ cell to reach $>20 \%$ cell efficiency.

Table 3: PC1D parameters that model the high efficiency $100 \Omega /$ sq textured FZ cells.

\begin{tabular}{|l|c|}
\hline \multicolumn{1}{|c|}{ Cell Parameters } & Tex. $100 \mathrm{Q} / \mathrm{sq}$ FZ \\
\hline$\tau_{\text {bulk }}(\mu \mathrm{s})$ & 250 \\
\hline $\mathrm{BSRV}(\mathrm{cm} / \mathrm{s})$ & 600 \\
\hline $\mathrm{R}_{\text {back }}(\%)$ & 61.5 \\
\hline $\mathrm{FSRV}(\mathrm{cm} / \mathrm{s})$ & 60,000 \\
\hline$J_{\mathrm{o} 2}\left(\mathrm{nA} / \mathrm{cm}^{2}\right)$ & 18 \\
\hline modelled $\mathrm{V}_{\mathrm{oc}}(\mathrm{m} \mathrm{V})$ & 639 \\
\hline modelled $\mathrm{J}_{\mathrm{sc}}\left(\mathrm{mA}_{\mathrm{cm}}{ }^{2}\right)$ & 37.1 \\
\hline modelled $\mathrm{FF}$ & 0.785 \\
\hline modelled $\eta(\%)$ & 18.6 \\
\hline
\end{tabular}

\section{CONCLUSION}

Our results show synergism between high sheetresistance emitter and a textured front-surface, which results in a greater efficiency enhancement due to the lightly doped textured emitter versus the enhancement due to the lightly doped emitter for planar cells. This is mainly attributed to the greater increase in FSRV due to texturing of the heavily doped emitters. The textured surface also shows more robustness in achieving consistently low series resistance compared with the planar emitter surface due to the ease of the $\mathrm{Ag}$ crystallite precipitation and contact formation at the tips of the texture pyramids. This work resulted in a high FF of 0.784 on $100 \Omega / s q$ textured emitter and a record efficiency of $18.8 \%$ using a high-throughput SP contact co-firing process.

\section{ACKNOWLEDGMENTS}

This work was supported by NREL contract No. AAT-231605-02. The authors would like to thank Bobby To and Tom Moriarty at NREL for performing SEM and IV measurements, respectively.

\section{REFERENCES}

[1] J. Szlufcik, F. Duerinckx, E. Van Kerschaver, and J. Nijs, "Advanced Industrial Technologies for Multicrystalline Silicon Solar Cells," $17^{\text {th }}$ EU PVSEC, 2001, pp. 1271-1276.

[2] K. A. Münzer, K. H. Eisenthrith, R. E. Schlosser, and M. G. Winstel, "18\%-PEBSCO-Silicon Solar Cells for Manufacturing," $17^{\text {th }}$ EU PVSEC, 2001, pp. 1363-1366.

[3] J. Nijs, E. Demesmaeker, J. Szlufcik, J. Poortmans, L. Frisson, K. De Clerq, M. Ghannam, R. Mertens, and R. Van Overstraeten, "Latest Efficiency Results with the Screen-printing Technology and Comparison with the Buried-Contact Structure," $1^{\text {st }}$ WCPEC, 1994, pp. 12421249.

[4] C. Schmiga, J. Schmidt, A. Metz, A. Endrös, and R. Hezel, "17.6\% Efficient Tricrystalline Silicon Solar Cells with Spatially Uniform Texture," Prog. Photovolt: Res. Appl., 11, 2003, pp. 33-38.

[5] M. M. Hilali, A. Rohatgi and S. Asher, "Development of Screen-Printed Silcon Solar Cells with High Fill Factors on $100 \Omega /$ sq Emitters," IEEE Trans. on Elect. Dev., 51, no. 6, 2004, pp. 948-955.

[6] P. A. Basore, "Extended Spectral Analysis of Internal Quantum Efficiency," $23^{\text {rd }}$ IEEE PVSC, 1993, pp.147152.

[7] A. W. Weeber, A. R. Burgers, M. J. A. A. Goris, M. Koppes, E. J. Koppen, H. C. Rieffe, W. J. Soppe, C. J. J. Tool, and J. H. Bultman, "16\% mc-Si Cell Efficiencies Using Industrial In-line Processing," $19^{\text {th }}$ EU PVSEC, 2004, in press. 